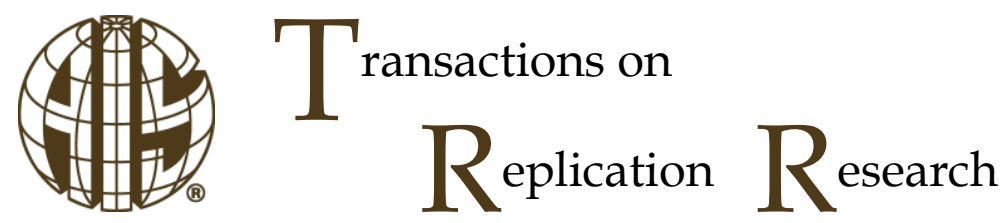

\title{
Empirical Testing of Resistance and Misuse Factors Contributing to Instructors' Use of E-Learning Systems in Saudi Arabia
}

\author{
Saleh Alharthi \\ Taif University \\ sa.alharthi2@tu.edu.sa
}

\author{
Yair Levy, PhD \\ Nova Southeastern University \\ levyy@nova.edu
}

\author{
Mansour Awaji \\ Jazan University \\ mawaji@jazanu.edu.sa
}

Abstract:

The purpose of this study was to conceptually replicate the model proposed by Bhatnagar, Madden, and Levy (2016) in a new context of e-learning systems usage and to examine the underlying resistance, misuse, and computer selfefficacy constructs that may contribute to instructors' usage of e-learning systems in Saudi Arabia. For this study, the original instrument was adapted, the Institutional Review Board (IRB) approval was obtained, data from 187 instructors that use e-learning systems were collected, and the model was analyzed using the Partial Least Squares (PLS). This study demonstrates higher overall model predictability than the original model and has stronger relationships between the constructs. The results show that computer self-efficacy and resistance to use the system contribute significantly to system usage, which are contrary to the original study's results that were in the context of secured medical teleconferencing. Additionally, computer self-efficacy appears to demonstrate a significant positive impact on ethical severity of misusing the systems, which is also a contrary to the original study's results. The results of this study indicate that context matters in IS usage, especially when there is a difference between IS used for exchange of private and personal information like medical teleconferencing, compared with an IS used as a productivity tool. However, both studies indicate that the ethical severity of misusing the systems has no significant impact on system usage, which may suggest that such relationship may be mediated by another construct and may call for further research. Discussions and conclusions are provided.

Keywords: E-learning System, Computer Self-Efficacy, Resistance to Use IS, E-learning Usage, Saudi Instructors

The manuscript was received 01/12/2017 and was with the authors 8 months for 3 revisions. 


\section{Introduction}

The use of Information Systems (IS) in higher education is over three decades old now in western countries, such as the United States (US), but is considered to be in an early stage in developing countries, including those in the Arab world (Khasawneh, 2015). The adoption and use of technologies in Arab countries in contrast to other countries in North America and Europe are still at a premature stage (Khasawneh \& Stafford, 2008; Rasmy, Tharwat, \& Ashraf, 2005; Rhema, Miliszewska, \& Sztendur, 2013). Moreover, usage of IS in Arab countries has not been fully researched as it has been in western countries (Khasawneh, 2015). E-learning systems have been growing in popularity among higher educational institutions, while it has been used as an assistive technology to supplement on-campus courses, as the primary delivery for fully-online courses, or even as a vehicle for corporate training in business organizations (Levy, Ramim, \& Hackney, 2013). However, the adoption of e-learning systems by higher educational institutes in Arab countries is still far behind the rest of the western world (Rhema et al., 2013).

Educational institutions in the Arab world confront distinctive challenges compared to western countries and must explore what influence instructors' usage of e-learning systems (Bhuasiri, Xaymoungkhoun, Zo, Rho, \& Ciganek, 2012). Furthermore, while educational institutions in Arab countries are embracing and implementing e-learning systems, instructors appear hesitant to use it either for fully-online or as an assistive technology to supplement on-campus courses (Rhema et al., 2013). Additionally, prior research indicates that there is a limited number of research studies on the perspectives of e-learning among users in developing countries (Rhema et al., 2013). Most of the prior research has investigated the concept of elearning systems from a western perspective; however, the Arab world receives very little attention in the literature (Al-alak \& Alnawas, 2011; Bhuasiri et al., 2012). In addition, there is a lack of the understanding for the resistance and misuse factors that influence instructors' usage of e-learning systems (Al-alak \& Alnawas, 2011). More specifically, in Saudi Arabia (as the population of this study), most of the e-learning systems studies were conducted from students' perspectives (Alharbi \& Drew, 2014). However, little attention has been paid to instructors' use of IS. This study argues that the usage of e-learning systems by instructors in Arab countries will enhance their ability to advance their technology skills and help teach the young generation the skills needed to acquire knowledge in today's digital age.

In this study, an attempt was made to conceptually replicate the study conducted by Bhatnagar, Madden, and Levy (2016), who studied the factors that contributed to patient use of medical teleconferencing in the US. Specifically, this study replicated the same conceptual model by Bhatnagar et al. (2016) but with a different type of technology (e-learning systems) and in a different environment (Arab countries). Moreover, the influence of the factors behind the use of e-learning systems by instructors in Saudi universities remains unexplored, and, thus, appears to be warranted for additional research.

The purpose of this study was to examine the underlying resistance, misuse, and computer self-efficacy factors that influence instructors' usage of e-learning systems in Saudi Arabia. More specifically, this study intended to measure Saudi Arabian instructors' aforementioned constructs along with usage of e-learning systems with the instrument used by Bhatnagar et al. (2016) with minor changes from the context of medical teleconferencing systems to e-learning systems. The significance of this study lies in the fact that it is among the first exploratory research, to our knowledge, that examines the factors that influence instructors' usage of e-learning systems in Saudi Arabia. The contribution of this study is shown in adopting a model that may be used to explore the e-learning systems usage in different countries in the Arab world.

\section{Hypotheses}

This study empirically tested the impact of the three aforementioned constructs that appear to contribute to the use of e-learning systems by instructors in Saudi universities (see Figure1). 


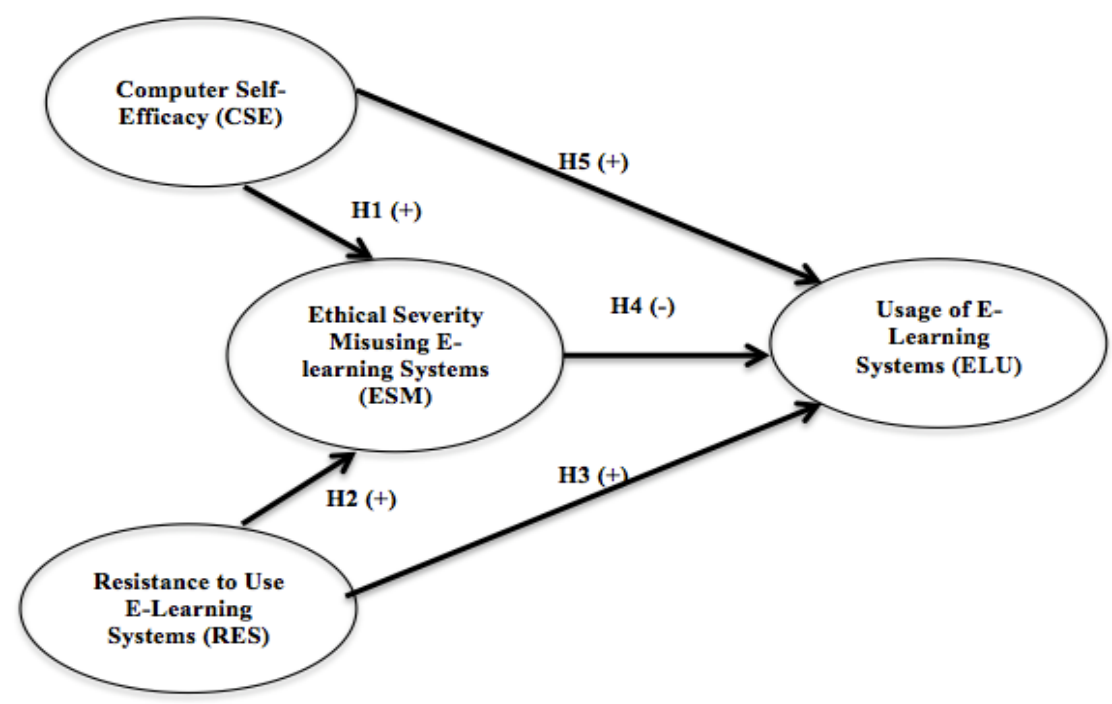

Figure1. Conceptual Research Map of Factors to Predict Usage of E-Learning Systems (adapted from Bhatnagar et al., 2016)

Computer self-efficacy has been widely used as a predictor to measure an individual's beliefs about their capabilities to expertly use computers to perform a task (Bhatnagar et al., 2016; Celik \& Yesilyurt, 2013; Dicke et al., 2014). Ethical severity of misusing IS is a measurement of the user's perceived ethical severity of IS misuse through cyber-attacks (Levy et al., 2013). Resistance to use IS is "define[d] as opposition of a user to change associated with a new IS" (Kim \& Kankanhalli, 2009, p. 568). IS usage is mainly measuring the time that the user spends using the system (Bajaj, 1998). Prior research used different factors and methods to measure their impact on IS usage to explore the factors that influence IS users to use the system (Bhatnagar et al., 2016; Hou, 2012; Lin, Chiou, Chen, \& Yang, 2016).

The same five hypotheses that Bhatnagar et al. (2016) examined were tested but in the context of e-learning systems are:

Hypothesis 1: Computer self-efficacy (CSE) of e-learning systems users will exert a positive and significant influence on ethical severity of misusing e-learning systems (ESM).

Hypothesis 2: Resistance to use e-learning systems (RES) will exert a positive and significant influence on ethical severity of misusing e-learning systems (ESM).

Hypothesis 3: Resistance to use e-learning systems (RES) will exert a positive and significant influence on usage of e-learning systems (ISU).

Hypothesis 4: Ethical severity of misusing e-learning systems (ESM) will exert a negative and significant influence on usage of e-learning systems (ELSU).

Hypothesis 5: Computer self-efficacy (CSE) of e-learning systems users will exert a positive and significant influence on usage of e-learning systems (ELSU).

\section{Research Method}

This study precisely followed the research method carried out by the original study of Bhatnagar et al. (2016) by collecting quantitative data using the survey instrument (see Appendix A) that was used in the conceptually replicated study. The four constructs were computer self-efficacy (Torkzadeh \& Lee, 2003), ethical severity of misusing IS (Levy et al., 2013), resistance to use IS as independent variables (Levy \& Danet, 2012), and IS usage as the dependent variable (Levy \& Danet, 2012). Additionally, the items for the constructs of resistance to use IS and ethical severity of misusing IS had a modified section headers than these obvious terms to reduction participants' bias. Moreover, the constructs items were set in the same way as in the items in Bhatnagar et al. (2016) but adjusted the name of the IS used from "video medical teleconferencing" to "e-learning system". Furthermore, the construct of resistance to use IS was set the 
same as in the original study of Bhatnagar et al. (2016) where increases in the measure indicates reduced resistance.

This study sample included 187 participants (see Table 1) that are university faculty members (instructors) form Saudi Arabia. The data analysis followed several pre-analysis data screening steps to ensure the validity of the data. Such pre-analysis data screening steps included, for example, the identification of missing data, response-sets (when users mark on all items the same score), and multivariate outliers, which is the same as was performed in the original study of Bhatnagar et al. (2016). Then, the Partial Least Squares (PLS) using SmartPLS was used to analyze the data for model fit and hypotheses testing.

\begin{tabular}{|l|l|l|}
\hline \multicolumn{2}{|c|}{ Table 1. Descriptive Statistics and Demographics of Participants (N=187) } \\
\hline Item & Frequency & Percentage (\%) \\
\hline Gender & & \\
Male & 118 & $63 \%$ \\
Female & 69 & $37 \%$ \\
\hline Age (Years) & & \\
20 or below & 0 & $0 \%$ \\
$22-31$ & 76 & $41 \%$ \\
$32-41$ & 71 & $38 \%$ \\
$42-51$ & 23 & $12 \%$ \\
$52-61$ & 15 & $8 \%$ \\
$62-71$ & 2 & $1 \%$ \\
72 and over & 0 & $0 \%$ \\
\hline Years of computer use (Years) & & \\
Under 1 year & 4 & $3 \%$ \\
$2-5$ & 13 & $7 \%$ \\
6-10 & 36 & $19 \%$ \\
$11-15$ & 53 & $28 \%$ \\
16-20 & 44 & $24 \%$ \\
Over 20 & 37 & $20 \%$ \\
\hline Position & & \\
Teaching assistance & 36 & $19 \%$ \\
Lecturer & 100 & $54 \%$ \\
Adjunct professor & 1 & $1 \%$ \\
Assistant Professor & 37 & $20 \%$ \\
Associate Professor & 6 & $3 \%$ \\
Professor & 7 & $4 \%$ \\
\hline
\end{tabular}

\section{Research Results}

\subsection{The Model Measurement}

A confirmatory factor analysis (CFA) was conducted, using the PLS technique. This study used Cronbach's Alpha as an indicator for reliability estimates of each construct. According to DeVellis (2016), Cronbach's Alpha greater than 0.7 is acceptable. The Cronbach's Alpha of CSE, ELSU, ESM, and RES in this study were $0.85,0.95,0.96$, and 0.81 respectively (Table 2 ), which indicates a high reliability for all constructs. In addition, to assess the internal reliability, a composite reliability (CR) indicator was used, and the results demonstrate that all constructs had high internal reliability values, which are higher than 0.7 as shown in (Table 2). The values of Cronbach's Alpha and CR were almost the same as those reported by Bhatnagar et al. (2016) as shown in (Table 2).

Table 2. Results of the Reliability and Validity Tests for Both the Original Study and the Present Study
(N=187)




\begin{tabular}{|l|l|l|l|l|l|l|}
\hline & Present study & 3 & 0.77484 & 0.910959 & & 0.854 \\
\hline \multirow{2}{*}{ ELSU } & Bhatnagar et al. (2016) & 9 & 0.89362 & 0.986939 & 0.142772 & 0.985 \\
\cline { 2 - 7 } & Present study & 9 & 0.70477 & 0.955511 & 0.274644 & 0.948 \\
\hline \multirow{2}{*}{ ESM } & Bhatnagar et al. (2016) & 5 & 0.98546 & 0.997059 & 0.006576 & 0.996 \\
\cline { 2 - 7 } & Present study & 5 & 0.862075 & 0.968983 & 0.210665 & 0.960 \\
\hline \multirow{2}{*}{ RES } & Bhatnagar et al. (2016) & 7 & 0.54856 & 0.894297 & & 0.874 \\
\cline { 2 - 7 } & Present study & 7 & 0.47421 & 0.856952 & & 0.805 \\
\hline
\end{tabular}

The average variance extracted (AVE) was used to assess the convergent validity (Hair et al., 2016). The values of AVE for CSE, ELSU, ESM, and RES were $0.77,0.70,0.86$, and 0.47 respectively, which indicate a high convergent validity for all constructs. The values of AVE were almost the same as those reported by Bhatnagar et al. (2016) as shown in (Table 2). Furthermore, the cross loadings were used to assess the discriminant validity (Hair, Hult, Ringle, \& Sarstedt, 2016). As result, the cross loadings values demonstrate that the discriminant validity was met (Table 3).

\begin{tabular}{|l|l|l|l|l|}
\hline \multicolumn{5}{|c|}{ Table 3. Cross-Loading of Construct Items (N=187) } \\
\hline & CSE & ELSU & ESM & RES \\
\hline CSE1 & $\mathbf{0 . 9 3 8 4 8 8}$ & 0.435820 & 0.452118 & 0.524144 \\
\hline CSE2 & $\mathbf{0 . 9 3 2 4 7 0}$ & 0.385594 & 0.412713 & 0.482204 \\
\hline CSE3 & $\mathbf{0 . 7 5 7 8 1 5}$ & 0.247653 & 0.276351 & 0.395751 \\
\hline ELSU1 & 0.444145 & $\mathbf{0 . 8 3 0 6 4 2}$ & 0.353895 & 0.477207 \\
\hline ELSU2 & 0.386994 & $\mathbf{0 . 8 1 7 9 2 7}$ & 0.235159 & 0.435924 \\
\hline ELSU3 & 0.311330 & $\mathbf{0 . 8 6 6 8 7 8}$ & 0.137455 & 0.404685 \\
\hline ELSU4 & 0.362209 & $\mathbf{0 . 8 4 0 6 3 1}$ & 0.170811 & 0.440273 \\
\hline ELSU5 & 0.328333 & $\mathbf{0 . 8 4 5 5 3 7}$ & 0.171184 & 0.398637 \\
\hline ELSU6 & 0.224169 & $\mathbf{0 . 8 1 4 8 4 9}$ & 0.061175 & 0.363075 \\
\hline ELSU7 & 0.250805 & $\mathbf{0 . 8 4 0 3 4 4}$ & 0.039256 & 0.380666 \\
\hline ELSU8 & 0.359046 & $\mathbf{0 . 8 5 5 5 7 8}$ & 0.202428 & 0.377959 \\
\hline ELSU9 & 0.419557 & $\mathbf{0 . 8 4 1 8 5 9}$ & 0.252070 & 0.398315 \\
\hline ESM1 & 0.432398 & 0.266832 & $\mathbf{0 . 9 3 2 8 1 2}$ & 0.299281 \\
\hline ESM2 & 0.403657 & 0.244550 & $\mathbf{0 . 8 9 4 5 1 8}$ & 0.310156 \\
\hline ESM3 & 0.419227 & 0.167349 & $\mathbf{0 . 9 2 8 9 3 6}$ & 0.306477 \\
\hline ESM4 & 0.417968 & 0.192264 & $\mathbf{0 . 9 4 7 3 5 4}$ & 0.338700 \\
\hline ESM5 & 0.380703 & 0.170941 & $\mathbf{0 . 9 3 7 9 0 9}$ & 0.312384 \\
\hline RES1 & 0.505911 & 0.443252 & 0.362911 & $\mathbf{0 . 8 2 1 4 9 1}$ \\
\hline RES2 & 0.448911 & 0.474567 & 0.224135 & $\mathbf{0 . 8 0 0 4 0 0}$ \\
\hline RES3 & 0.354938 & 0.215711 & 0.259113 & $\mathbf{0 . 7 2 7 5 5 8}$ \\
\hline RES4 & 0.340746 & 0.287823 & 0.202725 & $\mathbf{0 . 6 8 0 5 2 9}$ \\
\hline RES5 & 0.198374 & 0.245268 & 0.061262 & $\mathbf{0 . 3 2 7 3 3 0}$ \\
\hline RES6 & 0.223783 & 0.199808 & 0.091010 & $\mathbf{0 . 6 0 2 6 9 9}$ \\
\hline RES7 & 0.366478 & 0.356982 & 0.283554 & $\mathbf{0 . 7 3 5 6 1 3}$ \\
\hline & & & & \\
\hline
\end{tabular}




\subsection{The Model Estimation}

The model was estimated by using SmartPLS and representing the $\mathrm{R}^{\wedge} 2$ and path coefficient analysis (Hair et al., 2016). The $\mathrm{R}^{\wedge} 2$ indicates the quality of the structural model. In the current study, the value of $\mathrm{R}^{\wedge} 2$ demonstrated the exogenous latent variables (CSE, ESM, \& RES) collective effects on the endogenous latent variable (ELSU). As shown in Figure 2, the $\mathrm{R}^{\wedge} 2$ of ELSU has a value of 0.27 , which is slightly above the threshold of 0.25 of acceptable value and shows that the overall model is acceptable (Hair et al., 2016). In contrast, the $\mathrm{R}^{\wedge} 2 \backslash$ value of IS usage in the original study by Bhatnagar et al. (2016) was 0.143 , which indicated an overall weak model.

A path coefficient is used to measure the relationships between constructs in the structural model (Hair et al., 2016). In the current study, the results show that two path coefficients are not significant (RES $\rightarrow$ ESM, $\& \mathrm{ESM} \rightarrow$ ELSU), while three path coefficients demonstrated that are significant (CSE $\rightarrow$ ESM, RES $\rightarrow$ ELSU, \& CSE $\rightarrow$ ELSU) as shown in (Table 4). In contrast, the results reported by Bhatnagar et al. (2016) have only two significant path coefficients. In addition, the original study by Bhatnagar et al. (2016) reported that CSE (H5) had negative effects on IS usage, which is a contrary to the assumption that was proposed to have a positive effect. However, in the current study, CSE (H5) has a positive effect on ELSU as hypothesized.

The $p$-value is used to demonstrate the significance level in the hypotheses testing. A lower $p$-value (typically $\leq 0.05,0.01, \& 0.001$ ) demonstrates stronger evidence against the null hypothesis; thus, the $p$ value indicates that the hypothesis is supported. In the current study, the SmartPLS bootstrapping was utilized to generate the $\mathrm{p}$-values for all paths. The $\mathrm{p}$-value for $\mathrm{H} 1, \mathrm{H} 2, \mathrm{H} 3, \mathrm{H} 4$, and $\mathrm{H} 5$ were $<0.001,=0.094$, $<0.001,=0.481$, and $=0.034$, respectively. The result shows that $\mathrm{H} 1, \mathrm{H} 3$, and $\mathrm{H} 5$ are significant, while $\mathrm{H} 2$ and $\mathrm{H} 4$ are not significant. In contrast, the results reported by Bhatnagar et al. (2016) showed that only two hypotheses were supported ( $\mathrm{H} 3$ \& $\mathrm{H} 5)$, while in the current study, $\mathrm{H} 1, \mathrm{H} 3$, and $\mathrm{H} 5$ were supported.

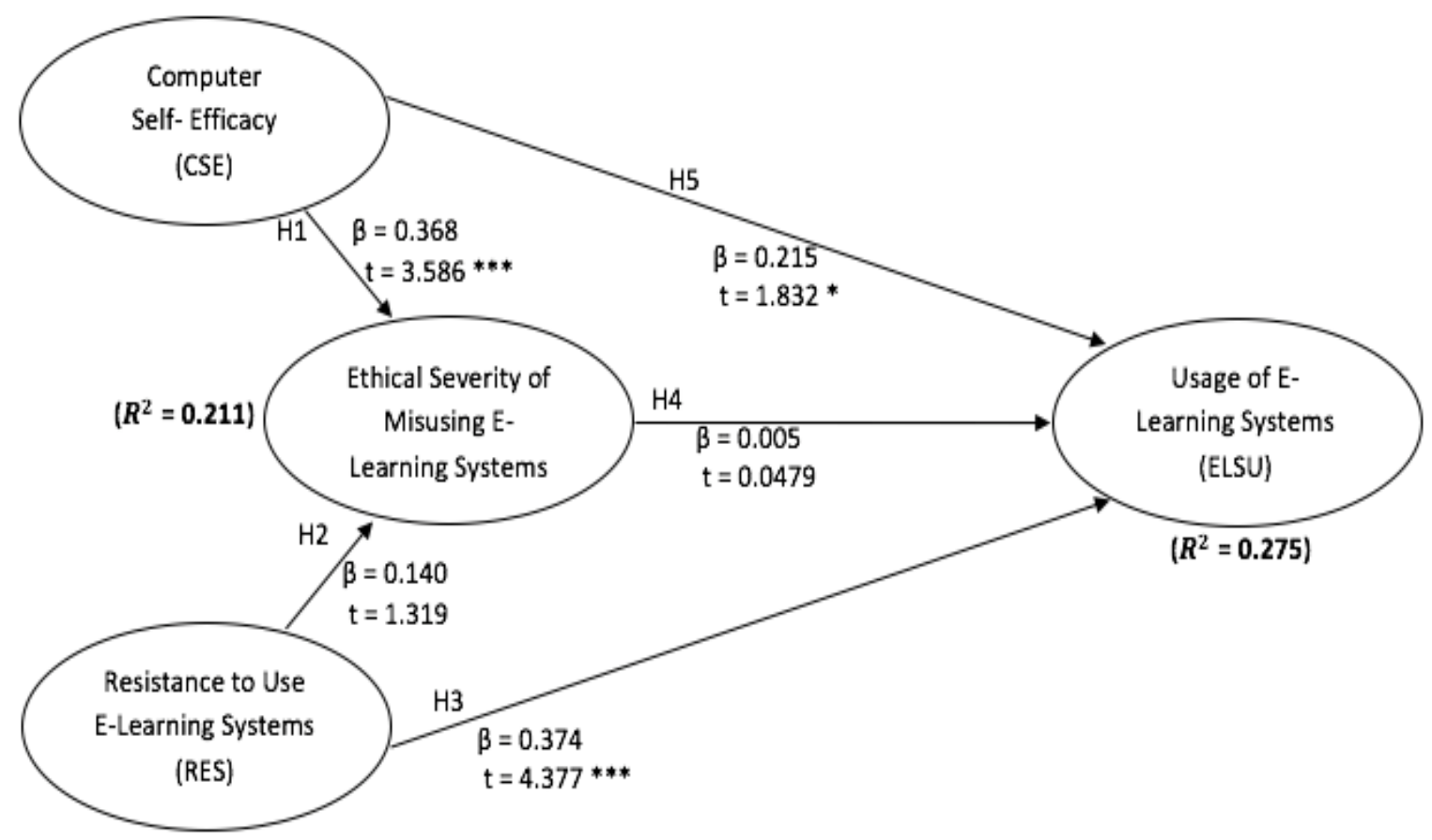

Figure 2. Results of PLS Analysis for Replication of Bhatnagar et al. (2016) study (N=187) 
Table 4. Results of PLS Analysis for Each Variable for Both the Original Study and the Present Study

\begin{tabular}{|c|c|c|c|c|c|c|}
\hline $\begin{array}{l}\text { Structural paths in } \\
\text { model }\end{array}$ & Study & Sign & $\begin{array}{l}\text { PLS path } \\
\text { coefficient }\end{array}$ & t-statistic & $p$-value & $\begin{array}{l}\text { Significance } \\
\text { level }\end{array}$ \\
\hline \multirow{2}{*}{$\mathrm{H} 1: \mathrm{CSE} \rightarrow \mathrm{ESM}$} & Bhatnagar et al. (2016) & + & 0.013881 & 0.181739 & 0.428 & NS \\
\hline & Present study & + & 0.368304 & 3.586312 & 0.000 & $* * *$ \\
\hline \multirow{2}{*}{ H2: RES $\rightarrow$ ESM } & Bhatnagar et al. (2016) & - & -0.076103 & 0.975783 & 0.165 & NS \\
\hline & Present study & + & 0.140272 & 1.319029 & 0.094 & NS \\
\hline \multirow{2}{*}{ H3: RES $\rightarrow$ ELSU } & Bhatnagar et al. (2016) & - & -0.342286 & 4.379136 & 0.000 & 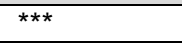 \\
\hline & Present study & + & 0.374330 & 4.377462 & 0.000 & *** \\
\hline \multirow{2}{*}{ H4: ESM $\rightarrow$ ELSU } & Bhatnagar et al. (2016) & - & -0.016031 & 0.305523 & 0.380 & NS \\
\hline & Present study & + & 0.004955 & 0.047927 & 0.481 & NS \\
\hline \multirow{2}{*}{ H5: CSE $\rightarrow$ ELSU } & Bhatnagar et al. (2016) & - & -0.281750 & 2.770990 & 0.003 & $* *$ \\
\hline & Present study & + & 0.214836 & 1.832561 & 0.035 & * \\
\hline \multicolumn{7}{|l|}{$\begin{array}{c}*-p<0.05 \\
{ }^{* *}-p<0.01 \\
* \star * \\
\text { NS - not significant }\end{array}$} \\
\hline
\end{tabular}

\subsection{Remarks About the Differences in the Results from the Original Study of Bhatnagar et al. (2016)}

The current study and the original study by Bhatnagar et al. (2016) have several similarities that include: the instruments, the model, and the data analysis. However, the two studies have been conducted in different contexts and using different IS that may provide additional theoretical rationale for the discrepancies in the results. Specifically, the original study by Bhatnagar et al. (2016) was focused on IS to enable personal medical assistance, i.e. privacy and personal health information focused, while this study was focused on IS as a productivity tool. In this study, we demonstrated some interesting results that are contradictory to the original study. While both studies have almost the same significance level on all model paths, four out of the five paths demonstrated opposite path coefficient signs (RES $\rightarrow$ ESM, RES $\rightarrow$ ELSU, $\mathrm{ESM} \rightarrow$ ELSU, \& CSE $\rightarrow$ ELSU). These differences derived primarily due to the type of IS that each study is focused on and the type of participants. The original study indicated that the findings were contrary to what was found in prior research, which, again, may be associated with the type of IS (i.e. personal/private/medical tool vs. productivity tool in this study). However, the findings in this study are more aligned with prior research that RES, ESM, and CSE have positive relationships with system usage. Thus, while the two studies are similar in many ways, one of the strongest outcomes of this replicative study is in the realization that the type and focus of the IS may indeed have a critical impact on the results of the model tested.

In summary, the current study demonstrates a better overall model predictability than the original overall model predictability, which is slightly above the acceptable threshold of 0.25 . In addition, the current study has better relationships between constructs in the structural model than in the original study. Having said that, we believe that no model will necessarily be an exact and complete match to the underlying phenomenon, however, the type of IS appears to be a significant variable that future researchers must take into consideration using constructs and models from prior literature. As noted in the original study by Bhatnagar et al. (2016), the focus was on IS used for communication of personal, private, and health information, where the model tested was not a good fit. However, in this replicative study, the IS used was mainly as a productivity tool, which appears to provide a reasonable model fit. While this model maybe interesting by itself and may deem further research, want to point out that many research studies in IS have been replicating, adjusting, or improving prior models found in IS literature with very limited, if any, attention given to the exact type of IS used in the prior literature the model was taken from and how it relates to their own study. As a result, we would like to use this replicative study results as a demonstration for the fact that the type of the IS studied, especially as it pertains to personal, private, and health information vs. one used as a productivity tool, is critical to the overall model fit. Thus, we would like to caution IS researchers, especially novice ones, to consider the potential differences between the type of IS used in the original literature they are using as foundation, and the type of IS they are planning to study in their own research. 


\section{Discussion}

The purpose of this study was to conceptually replicate the model proposed by Bhatnagar et al. (2016) to examine the factors that contribute to IS usage. The model was tested on a different type of IS than in the original study, while the original model was tested on IS used for communication of personal, private, and health information (medical teleconferencing \& e-health), the IS used in this study is e-learning systems. The results of the current study confirmed the reliability and validity of the model proposed that was initially validated by Bhatnagar et al. (2016). The original study adapted measurement items from prior research (Levy \& Danet, 2010; Levy \& Green, 2009; Levy et al., 2013). In the current study, we adapt the same measurement items to the context of e-learning systems. For example, we substituted the original question "I feel that video medical teleconferencing is an acceptable supplement to traditional medicine" with "I feel that an e-learning system is an acceptable supplement to the traditional university."

Our findings show that the constructs of CSE and RES have a significant positive contribution toward ELSU, which was similar to what was anticipated. We must note that RES was measured similar to the original study where increases in the measure indicates reduced resistance. We hypothesized that when users receive training and gain more knowledge about the use of e-learning systems, they will be more comfortable using it. Also, it was hypothesized that as resistance to use e-learning systems decreased (i.e. increase in the measure of the construct items), the more likely it was that the user would use e-learning systems. This confirms that the hypotheses $\mathrm{H} 5$ and $\mathrm{H} 3$ are supported. However, the results of the original study by Bhatnagar et al. (2016) demonstrated that CSE and RES have a significant negative contribution toward ELSU (note - same direction of the RES measure was used in both studies). The results indicate that type of IS and context appear to matter greatly in IS usage since it can change some of the constructs significance and contribution levels.

Furthermore, in the current study, the construct of CSE appears to demonstrate a significant positive contribution on ESM. It was hypothesized that the higher a user's CSE, the more possibly they would judge ethical misuse of IS severely, thus, restricting their use of e-learning systems. This confirmed that hypothesis $\mathrm{H} 1$ is supported, which is a contrary with the original study by Bhatnagar et al. (2016). Thus, the results again indicate that the type of IS studied and context appear to dictate the overall model fit, along with the results of the constructs relationships.

Similar to the original study by Bhatnagar et al. (2016), the construct of ESM in the current study appears to demonstrate no significant impact on ELSU. Also, RES appears to demonstrate no significant impact on ESM. This implies that the type of IS and context does not matter when considering the influence of ethical severity of misusing e-learning systems on IS usage or the influence of resistance to use e-learning systems on ethical severity of misusing e-learning systems.

The current study has interesting results compared to the original study. Although both studies have similar significance levels in almost all the path strengths, we found that they have different relationships, specifically, the sign of the path between constructs that result in reversed relationship on usage of IS. We believe these limited contradictory results were caused by two main differences: 1) difference in the type of IS used and the focus of the information used within the original and this study; 2) difference between participants' characteristics in both studies. Specifically, when it comes to the type of IS used, we observe that the original study was in the context of health IS focused on sharing of private, personal medical assistance, and private health information, while this study is in the context of e-learning, which is a productivity enhancing tool. Thus, we believe that such differences may contribute to the reverse signs that were observed. Furthermore, the difference between participants' characteristics in both studies may also have played a significant role in the discrepancies in the findings. Specifically, in the original study, $76 \%$ of the participants were between 42 and 71 years old; whereas, in the current study, $91 \%$ were between 22 and 51 years old. Also, $92 \%$ of the participants in the original study had 16 years or more of computer use, while $78 \%$ of the participants in the current study had between two and 20 years of computer use. This demonstrates that participants in the original study were older by the nature of the specific IS that the study focused on, given that most younger individuals appear to spend much less time to seeking medical advice. However, in the current study, the participants are younger and exploring opportunities to enhance their teaching performance by using a tool that may help their productivity. 


\section{Conclusion}

This study was intended to increase the external validity of the findings by Bhatnagar et al. (2016), which was in the context of medical teleconferencing (e-health) from the patients' perspective, to a new context of e-learning systems usage from the instructors' perspective. This study confirmed some of the hypotheses set forth by Bhatnagar et al. (2016), which can be generalized as shown in the results and discussion sections. However, both studies have some differences in the structural models, which should be further tested in future research. Using this model in different contexts and demographics will enrich our understanding of the factors that contribute to IS usage, especially, as it pertains to the relationship of ethical severity of IS misuse. Furthermore, we think that additional work is needed to investigate a revised model from the one studied both in the original work of Bhatnagar et al. (2016) and in our study here by developing and testing a model that possibly be an improved model that addresses both types of IS (health IS \& IS as productivity tool). Moreover, while this study was a replicative one and as such used the exact same model as in the original work of Bhatnagar et al. (2016), further research is needed to explore the possibility of removing some constructs and to add others in an attempt to improve the model so that it can work in both contexts.

The findings of this study, to our surprise, show that ethical considerations did not have as a major influence on IS use in either study. We can only speculate on why this might be. One possibility is that technologies presented by an authority (hospital or university) are considered to have already been examined for ethical issues and, therefore, do not need reexamination; another is that technologies have such obvious benefits in their use that long range ethical concerns seem overshadowed; finally, it is possible that users have been conditioned to simply not ask ethical questions, to consider that technology progress is inevitable and, therefore, to be used for better or worse. Apparently, we do not know based on our data, the effect of each of these possible influences, but it suggests that the question is worthy of further research, particularly in this era of disturbing and increasing concerns about cybersecurity. We recommend that additional research be conducted to further study why this construct was not a major impacting factor when it comes to IS usage of a productivity tool, especially, in the context of e-learning in Arab countries. Similar to any research study, this study had several limitations, which include a small sample size, the need to differentiate between the level of how valuable a productivity tool is to the participants' work-related tasks, and its impact on the model explored in these two studies. In spite of these limits, it is our hope that the data presented adds to the dialogue concerning the proposed model and leads to further testing and refinement thereof. 


\section{References}

Afifi, G. (2011). E-learning as an alternative strategy for tourism higher education in Egypt. Quality Assurance in Education, 19(4), 357-374.

Al-alak, B. A., \& Alnawas, I. A. (2011). Measuring the acceptance and adoption of e-learning by academic staff. Knowledge Management \& E-Learning: An International Journal, 3(2), 201-221.

Alebaikan, R., \&Troudi, S. (2010). Blended learning in Saudi universities: Challenges and perspectives. ALT Journal of Research in Learning Technology, 18(1), 49-59.

Alharbi, S., \& Drew, S. (2014). Using the technology acceptance model in understanding academics' behavioural intention to use learning management systems. International Journal of Advanced Computer Science and Applications, 5(1), 134-155.

Aggelidis, V. P., \& Chatzoglou, P. D. (2012). Hospital information systems: Measuring end user computing satisfaction (EUCS). Journal of biomedical informatics, 45(3), 566-579.

Bajaj A., \& Nidumolu S. R. (1998). A feedback model to understand information system usage. Information \& Management, 33(4), 213-224.

Bhatnagar, N., Madden, H., \& Levy, Y. (2016). Initial empirical testing of potential factors contributing to patient use of secure medical teleconferencing. Journal of Computer Information Systems, 1-7.

Bhuasiri, W., Xaymoungkhoun, O., Zo, H., Rho, J. J., \& Ciganek, A. P. (2012). Critical success factors for e-learning in developing countries: A comparative analysis between ICT experts and faculty. Computers \& Education, 58(2), 843-855.

Celik, V., \& Yesilyurt, E. (2013). Attitudes to technology, perceived computer self-efficacy and computer anxiety as predictors of computer supported education. Computers \& Education, 60(1), 148-158.

DeVellis, R. F. (2016). Scale development: Theory and applications (Vol. 26). Sage publications.

Dicke, T., Parker, P. D., Marsh, H. W., Kunter, M., Schmeck, A., \& Leutner, D. (2014). Self-efficacy in classroom management, classroom disturbances, and emotional exhaustion: A moderated mediation analysis of teacher candidates. Journal of Educational Psychology, 106(2), 569-583.

Doll, W. J., \& Torkzadeh, G. (1988). The measurement of end-user computing satisfaction. MIS Quarterly, 12(2), 259-274.

Hair Jr, J. F., Hult, G. T. M., Ringle, C., \& Sarstedt, M. (2016). A primer on partial least squares structural equation modeling (PLS-SEM). Sage Publications.

Hou, C. K. (2012). Examining the effect of user satisfaction on system usage and individual performance with business intelligence systems: An empirical study of Taiwan's electronics industry. International Journal of Information Management, 32(6), 560-573.

Khasawneh, M. (2015). Factors influence e-learning utilization in Jordanian universities-academic staff perspectives. Procedia-Social and Behavioral Sciences, 210, 170-180.

Khasawneh, A. M., \& Stafford, T. F. (2008). Mobile computing in developing nations: The case of use and adoption in Jordan. Proceedings of the 2008 Global Information Technology Management Conference, Atlanta, GA.

Kim, H. W., \& Kankanhalli, A. (2009). Investigating user resistance to information systems implementation: A status quo bias perspective. MIS Quarterly, 33(3), 567-582.

Leng, G. S., Lada, S., Muhammad, M. Z., Ibrahim, A. A. H. A., \& Amboala, T. (2011). An exploration of social networking sites (SNS) adoption in Malaysia using technology acceptance model (TAM), theory of planned behavior (TPB) and intrinsic motivation. Journal of Internet Banking and Commerce, 16(2), $1-27$.

Levy, Y., \& Danet, T. L. (2010). Implementation success model in government agencies: A case of a centralized identification system at NASA. International Journal of Information Systems in the Service Sector, 2(2), 19-32. 
Levy, Y., \& Green, B. D. (2009). An empirical study of computer self-efficacy and the technology acceptance model in the military: A case of a US Navy combat information system. Journal of Organizational and End User Computing, 21(3), 1-23.

Levy, Y., Ramim, M. M., \& Hackney, R. A. (2013). Assessing ethical severity of e-learning systems security attacks. Journal of Computer Information Systems, 53(3), 75-84.

Lin, H. C., Chiou, J. Y., Chen, C. C., \& Yang, C. W. (2016). Understanding the impact of nurses' perception and technological capability on nurses' satisfaction with nursing information system usage: A holistic perspective of alignment. Computers in Human Behavior, 57, 143-152.

Marnell, J. W., \& Levy, Y. (2014). Towards a model of factors affecting resistance to using multi-method authentication systems in higher-education environments. Information Security Education Journal, $1(1), 36-45$.

Rasmy, M. H., Tharwat, A., \& Ashraf, S. (2005, June). Enterprise resource planning (ERP) implementation in the Egyptian organizational context. In Proceedings of the EMCIS International Conference.

Rhema, A., Miliszewska, I., \& Sztendur, E. M. (2013, July). Attitudes towards e-learning and satisfaction with technology among engineering students and instructors in Libya. Proceeding of Informing Science \& IT Education Conference, 157-171.

Sukumaran, A. K. S. (2015). End user computing satisfaction instrument for a university website in India. International Journal of Business Information Systems, 20(4), 496-508.

Sugianto, L. F., \& Tojib, D. R. (2006). Modelling user satisfaction with an employee portal. International Journal of Business and Information, 1(2), 239-255.

Torkzadeh, G., \& Lee, J. (2003). Measures of perceived end-user computing skills. Information \& Management, 40(7), 607-615.

Zhou, T. (2013). Examining continuance usage of mobile Internet services from the perspective of resistance to change. Information Development, 30(1), 22-31. 


\section{Appendix A: Survey Instrument}

\section{Computer Self-Efficacy}

\begin{tabular}{ccccccc}
\hline 1 & 2 & 4 & 5 & 7 \\
$\begin{array}{c}\text { Strongly } \\
\text { disagree }\end{array}$ & Disagree & $\begin{array}{c}\text { Somewhat } \\
\text { disagree }\end{array}$ & $\begin{array}{c}\text { Neither agree } \\
\text { or disagree }\end{array}$ & $\begin{array}{c}\text { Somewhat } \\
\text { agree }\end{array}$ & $\begin{array}{c}6 \\
\text { Agree }\end{array}$ & $\begin{array}{c}\text { Strongly } \\
\text { agree }\end{array}$ \\
\hline
\end{tabular}

1.1 I am comfortable working with computers

1.2 If I am given some training, I can learn to use most computer programs

1.3 I can learn to use most computer programs just by reading the manuals and help

2. Resistance to Use E-Learning Systems (Title was "Perceived Use of E-Learning Systems" to participants to reduce bias)

\begin{tabular}{ccccccc}
\hline 1 & 2 & 3 & 4 & 5 & \\
$\begin{array}{c}\text { Strongly } \\
\text { disagree }\end{array}$ & Disagree & $\begin{array}{c}\text { Somewhat } \\
\text { disagree }\end{array}$ & $\begin{array}{c}\text { Neither } \\
\text { agree or } \\
\text { disagree }\end{array}$ & $\begin{array}{c}\text { Somewhat } \\
\text { agree }\end{array}$ & $\begin{array}{c}6 \\
\text { Agree }\end{array}$ & $\begin{array}{c}\text { Strongly } \\
\text { agree }\end{array}$ \\
\hline
\end{tabular}

2.1 I feel that e-learning system is an acceptable supplement to traditional university

2.2 I feel that e-learning system can solve most of student needs

2.3 I feel that e-learning system will not adversely alter existing instructor-student relationships

2.4 I feel the use of the e-learning system will be looked upon favorably by my employers

2.5 I feel the use of the e-learning system will decrease my absences from my job

2.6. I feel the use of the e-learning system will not change my outlook on my students' approach to learning

2.7 I feel the use of the e-learning system will not negatively degrade my students' learning

\section{Ethical Severity of Misusing E-Learning System (Title was "Security of E-Learning Systems" to participants to reduce bias)}

\begin{tabular}{ccccccc}
\hline 1 & 2 & 3 & 5 & 6 & 7 \\
$\begin{array}{c}\text { Extremely } \\
\text { ethical }\end{array}$ & $\begin{array}{c}\text { Slightly } \\
\text { ethical }\end{array}$ & $\begin{array}{c}\text { Somewhat } \\
\text { ethical }\end{array}$ & $\begin{array}{c}4 \\
\text { Neutral }\end{array}$ & $\begin{array}{c}\text { Somewhat } \\
\text { unethical }\end{array}$ & $\begin{array}{c}\text { Slightly } \\
\text { unethical }\end{array}$ & $\begin{array}{c}\text { Extremely } \\
\text { unethical }\end{array}$ \\
\hline
\end{tabular}

3.1 Hacking into the e-learning server is ...

3.2 Intercepting the e-learning communications or data is...

3.3 Unauthorized sharing of student records is...

3.4 Unauthorized access to personal data is...

3.5 Spoofing of e-learning emails is... **

** Email spoofing is the creation of email messages with a forged sender address.

\section{E-Learning Systems Usage}

\begin{tabular}{ccccccc}
\hline 1 & 2 & 3 & 4 & 5 & 6 \\
$\begin{array}{c}\text { Strongly } \\
\text { disagree }\end{array}$ & Disagree & $\begin{array}{c}\text { Somewhat } \\
\text { disagree }\end{array}$ & $\begin{array}{c}\text { Neither agree } \\
\text { or disagree }\end{array}$ & $\begin{array}{c}\text { Somewhat } \\
\text { agree }\end{array}$ & $\begin{array}{c}6 \\
\text { Agree }\end{array}$ & $\begin{array}{c}\text { Strongly } \\
\text { agree }\end{array}$ \\
\hline
\end{tabular}

$4.1 \mathrm{I}$ use the e-learning system to assist me in my teaching activities

4.2 I use the e-learning system to help explain the course content to my students

4.3 I use the e-learning system to help analyze students' performance

4.4 I use the e-learning system to control my course content

4.5 I use the e-learning system to help me manage my course content

4.6 I use the e-learning system to monitor student progress

4.7 I use the e-learning system to plan my course activities

4.8 I use the e-learning system to keep my students informed

4.9 I use the e-learning system to post course materials and announcements 


\section{Demographic Information}

5.1 Age

1. 20 or below

2. 22-31

3. $32-41$

4. $42-51$

5. $52-61$

6. $62-71$

7. 72 and over

5.2 Position

1. Teaching assistance

2. Lecturer

3. Adjunct professor

4. Assistant Professor

5. Associate Professor

6. Professor

\subsection{Gender}

Male

Female
5.4 Years of computer use

1. Under 1 year

2. 2-5

3. $6-10$

4. $11-15$

5. $16-20$

6. Over 20

5.5 Years of using E-learning systems in teaching

1. Under 1 year

2. $2-5$

3. $6-10$

4. $11-15$

5. $16-20$

6. Over 20

5.6 I use E-learning systems in teaching

1. Traditional courses

2. Online courses

3. Both traditional and online courses 


\section{About the Authors}

Saleh Alharthi is an Assistant Professor of Management Information Systems in the faculty of Business Administration as well as at Taif University, Saudi Aabia, the Vice Dean of Business Administration for training. He holds a BSc in Management Information Systems, a MSc in Information Systems Technology, and a Ph.D. in Information Systems from Nova Southeastern University. His interest interests include corporate performance, strategy execution, M-learning, and productivity.

Yair Levy is a Professor of Information Systems and Cybersecurity at the College of Engineering and Computing (CEC), at Nova Southeastern University(NSU), the director of the Center for Information Protection, Education, and Research (CIPhER), and chair of the Information Security Curriculum Committee at the college overseeing the Ph.D. program in Information Assurance (DIA), a DHS/NSA certified program as part of NSU's designation of National Center of Academic Excellence in Information Assurance/Cyber Defense. His research interests include cybersecurity, social engineering, cyber threat mitigation, cybersecurity skills and competencies, and user-authentication and privacy issues with Web-based and elearning systems.

Mansour Awaji is a Lecturer of Management Information Systems in the College of Business Administration at Jazan University, Saudi Arabia. He earned his Ph.D. in Information Systems from Nova Southeastern University. He also holds a B.S and M.S degrees both in Management Information Systems from King Abdulaziz University and Florida International University. His research interests include analytics, data science, and machine learning applications in education.

Copyright ( 2019 by the Association for Information Systems. Permission to make digital or hard copies of all or part of this work for personal or classroom use is granted without fee provided that copies are not made or distributed for profit or commercial advantage and that copies bear this notice and full citation on the first page. Copyright for components of this work owned by others than the Association for Information Systems must be honored. Abstracting with credit is permitted. To copy otherwise, to republish, to post on servers, or to redistribute to lists requires prior specific permission and/or fee. Request permission to publish from: AIS Administrative Office, P.O. Box 2712 Atlanta, GA, 30301-2712 Attn: Reprints or via e-mail from ais@aisnet.org. 